\title{
Educación superior indígena en Brasil. Políticas gubernamentales y demandas indígenas: diálogos y tensiones
}

\author{
Mariana Paladino
}

Este artículo se propone ofrecer un panorama de la situación actual de la educación superior indígena en Brasil, enfocándose en las recientes políticas gubernamentales de promoción o apoyo al acceso y permanencia de indígenas en este nivel de educación, así como en las iniciativas de algunas universidades públicas. También expone algunas demandas de los estudiantes indígenas y el sentido que adopta para ellos la formación superior.

PALABRAS CLAVE: pueblos indígenas, educación superior indígena, políticas indigenistas en Brasil, acción afirmativa, interculturalidad

\begin{abstract}
Indigenous Higher Education in Brazil. Governmental Policies and Indigenous Demands: Dialogs and Tensions

The aim of this article is to offer an overview of the current situation of indigenous higher education in Brazil, focusing on recent governmental policies regarding the promotion or support to the access and permanence of indigenous people in this educational level, and on initiatives of some public universities. It also puts forward a concise characterization of indigenous students' demands, and the sense that higher education has for them.
\end{abstract}

KEYWORDS: indigenous peoples, indigenous higher education, indigenist policies in Brazil, affirmative action, interculturalism

Mariana Paladino: Laboratorio de Investigaciones en Etnicidad, Cultura y Desarrollo, Universidad Federal de Río de Janeiro, Brasil marianapaladinorj@gmail.com 


\section{INTRODUCCIÓN}

$\mathrm{E}$ n Brasil, hasta fines de la década de 1990, el acceso de la población indígena a la educación superior era una cuestión prácticamente ausente de las agendas gubernamentales y no gubernamentales. $\mathrm{Si}$ bien había indígenas que estaban realizando esos estudios o ya los habían concluido - muchos de ellos vinculados al movimiento indígena-, no se asociaba la formación superior de manera tan directa, como en la actualidad, a una mejor y efectiva actuación en proyectos y acciones de interés para este movimiento o para el de las comunidades indígenas de modo general ${ }^{1}$. Tanto las acciones de las organizaciones no gubernamentales de apoyo, como las de las propias organizaciones indígenas, se centraban en la escuela primaria y en la construcción de lo que se ha llamado, desde la década de 1980, "educación intercultural, bilingüe, específica y diferenciada”. Esta denominación remite a nuevas representaciones, discursos y prácticas sobre la educación escolar destinada a los pueblos indígenas, promovidos principalmente por el tercer sector y generados en un contexto de intensa movilización por el reconocimiento de los derechos indígenas. La educación escolar promovida por los órganos indigenistas del Estado y por las agencias misioneras fue concebida como una herramienta de aculturación, catequesis y civilización ${ }^{2}$. Sin embargo, al mismo tiempo, y debido a la valorización y a la reivindicación de un mayor acceso a la escolarización, sostenidas por muchos indígenas en aquellos años, ésta pasó a ser entendida como un instrumento posible de lucha, reafirmación étnica, valorización y rescate de conocimientos tradicionales ${ }^{3}$.

\footnotetext{
${ }^{1}$ En este artículo serán utilizados de forma indistinta los términos indios o indígenas, ya que las dos formas son ampliamente usadas en Brasil para referirse a la población autóctona del país. A pesar de remitir a concepciones peyorativas de esta población y a la historia de la conquista europea, el propio movimiento indígena brasileño reconoce la denominación genérica de indio o indígena como una forma de promover una identidad común entre los diversos pueblos originarios, que facilita la unión y fortalece las luchas y reivindicación conjunta de sus derechos.

${ }^{2}$ Utilizaré palabras en cursivas para referirme a las categorías de los actores indígenas y no indígenas.

${ }^{3}$ En este artículo será utilizada la expresión "educación escolar indígena" y no simplemente "educación indígena", ya que en Brasil tienen significados diferentes. La educación indígena remite a los procesos
}

Acorde a esta nueva forma de entender la educación escolar, organizaciones no gubernamentales (ONG) se volcaron a la construcción de propuestas pedagógicas pertinentes a la realidad indígena, que valorizaran la cultura y, en los casos necesarios - de ocultamiento de la identidad o pérdida de los modos de vida tradicionales-, que la revitalizaran o rescataran (Paladino, 2001). Ciertas premisas como oír a los indios, la participación de las comunidades o la búsqueda de la autonomía, se transformaron en una retórica compartida por los agentes participantes en el indigenismo alternativo al oficial, $y$ moldearon y legitimaron sus prácticas. El quehacer de éstos se volcó a que los propios indios asumieran la construcción y conducción de este nuevo modelo de escuela. Por lo tanto, los esfuerzos se centraron en la formación y capacitación de los maestros que ya se desempeñaban en las escuelas de las comunidades, pero en general con escasa preparación o con modelos pedagógicos anquilosados, adquiridos en sus primeras experiencias escolares junto a misioneros o en las escuelas del Servicio de Protección a los Indios (SPI) o de la Fundación Nacional del Indio (Funai) ${ }^{4}$.

de socialización propios de cada etnia, a los sistemas de crianza y transmisión de conocimientos que siguen una lógica y dinámica diferente a la escolar.

${ }^{4}$ El SPI fue la primera agencia del Estado brasileño responsable de las políticas indigenistas. Instituida por el Decreto número $8.072 \mathrm{del} 20 \mathrm{de}$ julio de 1910, tuvo por finalidad tanto actuar para garantizar la supervivencia física de los indios y establecer una convivencia pacífica entre ellos y la población no indígena, como promover que adoptaran gradualmente hábitos "civilizados", fijándolos al territorio y enseñándoles técnicas agrícolas y oficios. Para esto, estableció en los territorios ocupados por los indios una estructura administrativa llamada "Postos indígenas", en los cuales se incluía un edificio escolar, donde se enseñaba a los niños la lengua portuguesa, se los alfabetizaba y entrenaba en oficios, con el doble objetivo de nacionalizarlos y transformarlos en futuros trabajadores. Véase Souza Lima (1995) para un estudio profundo de la actuación de este órgano indigenista. Inhabilitado en 1967, a partir de diversas denuncias de corrupción, fue sustituido por la Funai, que hasta 1992 concentró la asistencia a los pueblos indígenas en todas las áreas (tierra, producción, salud, educación, entre otras). La Funai propició, en la década de 1970, una enseñanza bilingüe en las escuelas de las comunidades indígenas, con el apoyo del Summer Institute of Linguistics (SIL). En 1969 se firmó el primer convenio entre la Funai y el SIL. Sin embargo, el ingreso de esta institución en Brasil es anterior; se remonta a 1954, cuando intentó establecer un convenio con el SPI. Debido a la ideología positivista de esta agencia, que no veía con buenos ojos la actuación de las misiones religiosas, no aceptó el convenio y decidió darle una orientación más lingüística a su labor, por lo cual firmó un convenio en 1957 con el Museo Nacional (Universidad Federal de Río de Janeiro) para realizar estudios sobre lenguas indígenas. 
Estos maestros legos eran llamados por el órgano indigenista oficial monitores indigenas bilingües, lo que remitía a una posición secundaria y subordinada a los maestros $b_{\text {blancos }}{ }^{5}$. En el proceso de lucha y articulación del movimiento indígena brasileño desarrollado a fines de la década de 1970 y en la de 1980, que incluyó la organización de los maestros indígenas en pro de su profesionalización, ellos empezaron a reivindicar y asumir la denominación de profesores indígenas ${ }^{6}$. Los primeros cursos destinados a su formación fueron llevados a cabo por ONG y financiados por agencias de cooperación internacional y agencias vinculadas con la Iglesia católica, como el Consejo Indigenista Misionario (Cimi) y la Operación Anchieta (OPAN), que en esa época se adherían a la propuesta misionera de la teología de la liberación.

Con el restablecimiento de la democracia, a mediados de la década de 1980, muchas de estas experiencias pioneras, que venían construyendo una identidad basada en un discurso de autonomía y oposición al modelo escolar de la Funai, comenzaron a buscar el reconocimiento estatal para que los maestros indígenas obtuvieran un título reconocido por el Estado y fueran contratados efectivamente, entre otros motivos. La sustitución de maestros blancos por indios en los cargos docentes de las escuelas ubicadas en territorio indígena fue una de las principales banderas de reivindicación que levantó el movimiento indígena en ese periodo, así como la capacitación de los segundos y la creación de cursos de magisterio que fueran de modalidad "específica, diferenciada, intercultural y bilingüe". Para ello, se establecieron acuerdos y sistemas de cooperación entre ONG indígenas e indigenistas, secretarías de educación de nivel provincial y municipal, universidades y la Funai, para la coordinación conjunta de esos cursos, que equivalían a una formación de nivel secundario (enseñanza media).

Asimismo, en distintas regiones del país se crearon carreras de magisterio para indígenas, con diferentes ca-

\footnotetext{
${ }^{5}$ Es la forma genérica que los pueblos indígenas utilizan para referirse a la población no indígena, incluyendo en esta denominación tanto a población mestiza como negra.

${ }^{6}$ Véase Ferreira (1992) y Silva (1998) para una visión histórica del movimiento de profesores indígenas en Brasil, especialmente de la región amazónica.
}

racterísticas y dinámicas, según las especificidades del movimiento indígena local y de las relaciones establecidas entre éste, las ONG y el Estado. En el año 2001 se creó el primer curso de magisterio de nivel superior específico para indígenas, al que se llamó “Terceiro Grau Indígena. Projeto de Formação de Professores Indigenas em Nível Superior" (Tercer grado indígena. Proyecto de formación de maestros indígenas de nivel superior). Fue implementado en el estado de Mato Grosso por la Universidad Provincial de Mato Grosso y por la Secretaría Provincial de Educación, con apoyo de la Funai. Después de éste se crearon otros cursos de nivel superior para la formación de maestros indígenas en otras regiones del país, llamados "licenciaturas interculturales" o "licenciaturas indígenas"7. Ya existen doce licenciaturas de este tipo en universidades públicas de nivel nacional o provincial. Al mismo tiempo, algunas universidades públicas y privadas del país han implementado acciones afirmativas para la inclusión de alumnos indígenas en las carreras comunes que ofrecen. Más adelante abundaremos en sus detalles.

Ahora, la educación superior ocupa un lugar prioritario en la agenda vinculada con la educación escolar del movimiento indígena y de las ONG de apoyo al indio, en relación con otras temáticas o problemáticas, como podría ser la insuficiente oferta escolar de nivel secundario existente en las aldeas indígenas o la baja calidad de la escuela primaria, entre otros asuntos. En este texto pretendo analizar brevemente el estado de la educación superior indígena en Brasil, centrando la exposición en las políticas y acciones gubernamentales, en las acciones de algunas universidades del país y en las principales demandas y problemáticas expresadas por los indígenas que estudian en esos ámbitos.

Es importante destacar que, aunque la educación superior indígena reciba una creciente atención por parte de diversos actores gubernamentales y no gubernamentales, aún hay pocas investigaciones de corte antropológico que analicen esta cuestión y que permitan entender

\footnotetext{
${ }^{7}$ Estas licenciaturas están destinadas sólo a estudiantes indígenas. Algunas únicamente a estudiantes de una etnia específica, aunque la mayoría atiende a estudiantes de varias etnias que conviven en la misma región.
} 
el impacto de esta formación en las identidades de los estudiantes, en las de sus familias o grupos de parentesco, y en el fortalecimiento de la actuación de las organizaciones indígenas. También existe poco conocimiento y análisis sobre las transformaciones que la presencia indígena y sus demandas están promoviendo en el espacio universitario, entre otros temas que requieren ser indagados. Este artículo, que parte de una investigación en curso, apunta a plantear un cuadro general de la cuestión y situar algunos temas para un futuro debate, los cuales merecen ser explorados con más profundidad en otros estudios.

\section{POLÍTICAS PÚBLICAS DE EDUCACIÓN SUPERIOR INDÍGENA. ENTRE CUOTAS Y LICENCIATURAS INTERCULTURALES}

De acuerdo con Souza Lima y Barroso-Hoffmann (2004), la actual demanda indígena de acceso a la educación superior responde a dos necesidades que han sido percibidas de forma separada, aunque están estrechamente vinculadas: la formación de maestros indígenas y la formación de cuadros en otras áreas de conocimiento.

La primera resulta, en gran parte, de la necesidad de ajustarse a las normativas y leyes que exigen la formación de maestros indígenas en el nivel superior. El Plan Nacional de Educación (Ley número 10.172, del 9 de enero de 2001) establece que en 2011 los docentes de la red escolar pública deberán estar formados en cursos de magisterio de nivel superior. Ya antes de este plan educativo gubernamental, la Resolución 03/99 del Ministerio de Educación y Cultura (MEC) determinaba el derecho de los maestros indígenas a ser formados de acuerdo con sus especificidades culturales y con los contextos en los que viven.

La demanda de educación superior en otras áreas de conocimiento se vincula, según los autores citados anteriormente, a la situación de las relaciones actuales entre pueblos indígenas y Estado, del cual resulta la necesidad de calificar cuadros dentro del movimiento indígena que puedan asumir procesos de interlocución e intervención en las políticas públicas en favor de los derechos e intereses de sus pueblos. También se requiere de una capacitación para dar cuenta de los desafíos surgidos a partir de los procesos contemporáneos de territorialización, para que los propios indígenas puedan administrar sus territorios y los proyectos de etnodesarrollo que en ellos se llevan a cabo.

A su vez, Luciano $(2006)^{8}$ llama la atención sobre el hecho de que la demanda de educación superior resulta del propio avance del proceso de escolarización vivido por los pueblos indígenas en Brasil, el cual se ha acelerado considerablemente en los últimos años. Las estadísticas son ilustrativas: la población indígena brasileña, según el último censo realizado por el Instituto Brasileño de Geografía y Estadística (IBGE), comprende a 740 mil individuos $(2001)^{9}$. El número de alumnos indígenas que está cursando la primaria en las aldeas pasó de 117 mil en 2002 a 164 mil en 2005. El número de alumnos que está en la educación media o secundaria pasó de 1187 en 2002 a 4749 en 2005. A estos datos habría que agregar la cantidad de indígenas que estudian en las primarias y secundarias de la ciudad, sobre quienes se sabe que son una presencia significativa, pero no hay estadísticas.

Junto con estas referencias sobre la creciente demanda indígena de acceso a la educación superior, es relevante destacar las representaciones que cada pueblo indígena tiene sobre este nivel educativo. A lo largo de mi investigación pude verificar que muchos jóvenes indígenas sienten una gran curiosidad por conocer un espacio extraño y distante, como lo era hasta hace poco el ámbito universitario, y que perciben el valor y la fuente de estatus que éste representa para los no indígenas. Considero que, en parte, éste es también un motivo de su interés, ya que

\footnotetext{
${ }^{8}$ Gersem dos Santos Luciano, de la etnia baniwa, es un líder de gran trayectoria en el movimiento indígena. Primer antropólogo indígena del país, se desempeña actualmente como coordinador de la Educación Escolar Indígena a nivel nacional, la cual depende de la Secretaría de Educación Continua, Alfabetización y Diversidad del Ministerio de Educación. Es también director de la organización indígena Centro Indígena de Estudios e Investigaciones.

${ }^{9}$ La población indígena, compuesta por 220 etnias que hablan 180 lenguas diferentes, representa $0.4 \%$ de la población brasileña, aunque este porcentaje varía mucho según las regiones. Por ejemplo, en la Amazonia, en algunos municipios, constituyen más de 50\% de la población. El Estado ha reconocido, a partir de la Constitución de 1988, el derecho de los indígenas a la ocupación y el uso de las tierras tradicionalmente habitadas por ellos. Según datos del Departamento de Tierras de la Funai de 2006, existían en Brasil 612 territorios indígenas reconocidos por el Estado, que totalizaban una extensión de 106373144 hectáreas, o sea, $12.49 \%$ del territorio brasileño.
} 


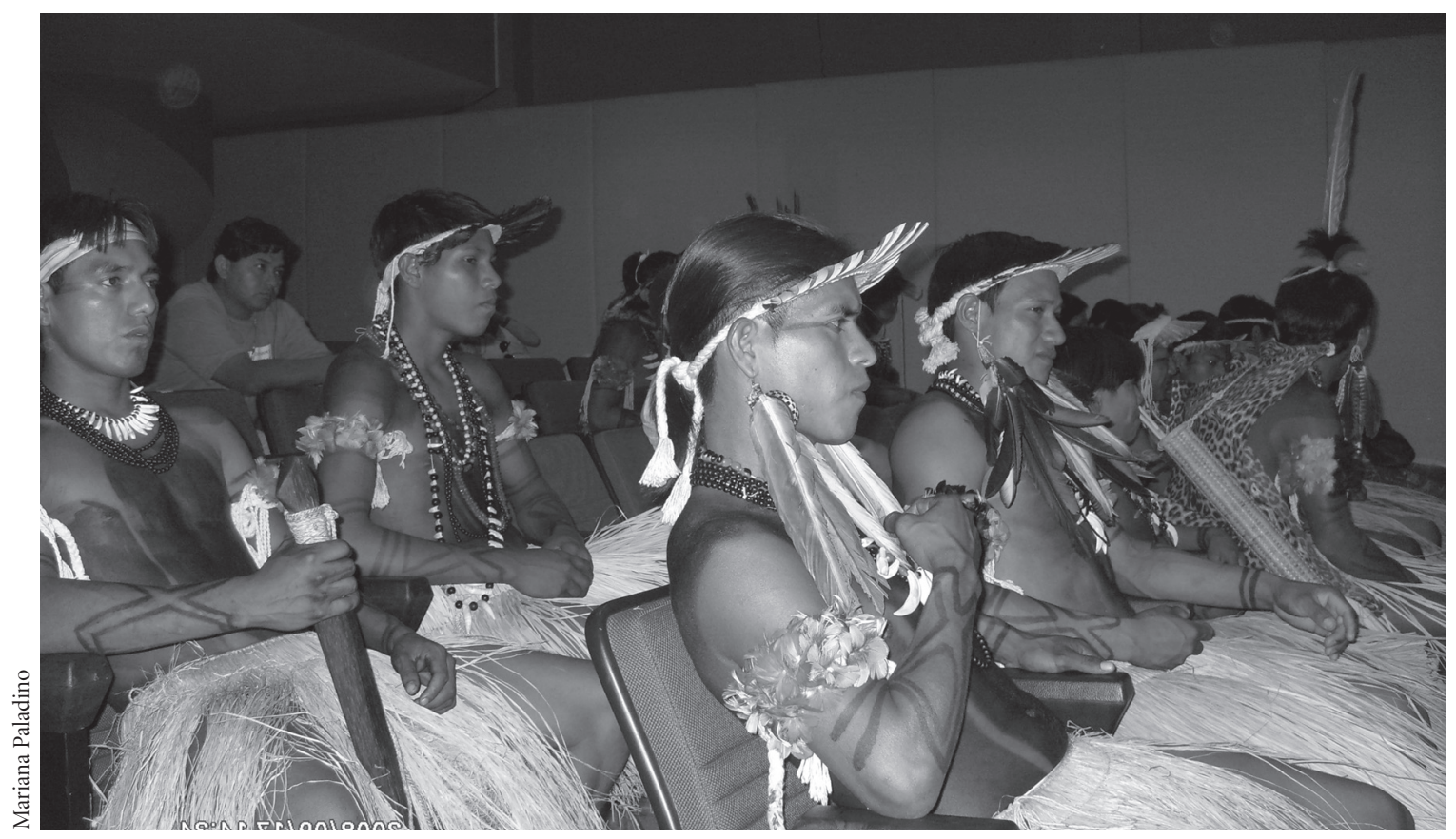

Jóvenes de la etnia umutina del estado de Mato Grosso, en el Seminario sobre el papel de la Universidad y de la formación académica bajo la óptica de los líderes y estudiantes indígenas, 16 al 18 de octubre de 2008, Brasilia.

asocian la posibilidad de ingresar a la universidad con una mejoría socioeconómica. Esta expectativa —muchas veces mencionada por los propios estudiantes indígenas con expresiones como "querer ser alguien en la vida" o "ir para adelante" - en mi opinión, no debe ser entendida de la misma forma en que es asumida por los estudiantes universitarios no indígenas. Es decir, no están en juego solamente expectativas de ascenso social individual, sino también el deseo de conquistar un bienestar familiar y colectivo, y acceder a una ciudadanía, entendida como la adquisición de los mismos derechos y espacios que tienen los sectores de la sociedad dominante.

\section{Políticas y acciones de apoyo a la educación superior indígena por parte de la Funai y el Ministerio de Educación}

La demanda indígena de educación superior adquirió una forma organizada recientemente. Las estrategias pa- ra ingresar y conseguir mantenerse durante los estudios universitarios eran sobre todo individuales. El único órgano de gobierno que atendía parcialmente esta demanda era, hasta fines de la década de 1990, la Funai, por medio de la concesión de auxilio financiero o becas a alumnos indígenas. Éstos destinaban esos recursos, por lo general, a pagar la matrícula y las mensualidades de las universidades privadas a las que asistían. Es importante aclarar que la mayoría de los estudiantes universitarios indígenas estaban inscritos — antes de la implementación de acciones afirmativas en las universidades públicas- en universidades privadas, por ser éstas de más fácil acceso que las públicas, las cuales someten a sus candidatos a exámenes de ingreso muy rigurosos y competitivos. En 2003, cuando todavía eran pocas las universidades públicas que habían implementado mecanismos para la inclusión de alumnos indígenas, la Funai estimaba que había alrededor de 1300 indígenas en la educación superior universitaria, de los cuales entre 60 y $70 \%$ estaba en instituciones privadas. 
Estas acciones de apoyo no formaban parte de una política del órgano indigenista de promoción de la educación superior indígena. Al contrario, ésta era vista de forma negativa, por suponer que propiciaría que el indio saliera de la comunidad, migrara y se insertara en el medio urbano para poder estudiar en alguna universidad, lo cual, además, promovería una formación individualista y distante de sus valores culturales. Por lo tanto, la concesión de becas se daba de forma individual, muchas veces con base en relaciones de clientelismo que los administradores regionales de la Funai establecían con algunos grupos o familias indígenas. Se sabía poco acerca de los criterios de adjudicación y administración del auxilio financiero a los alumnos indígenas, así como sobre la cantidad otorgada, el tipo de carreras realizadas o las trayectorias y posición social de los beneficiarios.

El apoyo de la Funai a estudiantes indígenas universitarios continúa, aunque a partir de la Portaría 63, del 23 de enero del 2006, se establecieron reglas para el otorgamiento de las becas. Entre éstas, consta el "desempeño académico" del alumno y también el requisito de que rante o después de la carrera junto con su comunidad o en alguna organización indígena. La Funai también busca incentivar que los indígenas estudien en las universidades públicas que han establecido políticas de acción afirmativa, por entender que son de mejor calidad que las universidades privadas, además de que representan un costo menor.

A comienzos de 2007, la Funai daba auxilio financiero a 1710 estudiantes indígenas universitarios. Según la jefa de la Coordinación General de Educación de ese órgano, en 2000 atendía sólo a 170 estudiantes, pero en los años siguientes se produjo un crecimiento explosivo en el ingreso de indígenas a la educación superior y aumentó la demanda de apoyo hacia la Funai. A pesar de la fuerte disminución del presupuesto que ha sufrido esta institución en los últimos quince años, ha establecido convenios con algunas universidades para garantizar acciones que promuevan la permanencia de los alumnos indígenas. En estos convenios se delimita una división de competencias. En general, la Funai se compromete a pagar becas integrales o parciales para que los alumnos cubran gastos de

vivienda y transporte, y facilita la adquisición de materiales didácticos. A su vez, la universidad se compromete —según los casos—a apoyar con alimentación gratuita en los comedores universitarios, gastos de fotocopias, asistencia médica y acompañamiento pedagógico y social ${ }^{10}$.

Uno de los aspectos cuestionables de la forma en que la Funai concede asistencia a los estudiantes indígenas es el requisito de presentar, en el momento de solicitar la beca, además de documentos que comprueben su identidad indígena (certificación de nacimiento emitida por la Funai), una declaración de la comunidad que dé fe del origen del candidato y del interés de la misma en su formación. También es un requisito la presentación de una propuesta de trabajo a ser desarrollada durante o después de la carrera junto con su comunidad o en una organización indígena, que cuente con el aval de sus líderes. Estos dos requisitos tienen como fin preservar el vínculo de los estudiantes con sus poblados de origen. Sin embargo, en mi opinión, supone la perspectiva de que la forma de vida actual de los indígenas se circunscribe al espacio comunitario. Por lo tanto, no se considera la complejidad de los procesos de territorialización por los que atraviesan los pueblos indígenas, entre los cuales se encuentran la migración urbana o los traslados frecuentes, y la residencia temporal en estancias o empresas de trabajo ${ }^{11}$. De esta forma opera una suerte de penalización para el indio que no vive en aldeas, pues no recibe el mismo tipo de asistencia ni se ve beneficiado por políticas públicas específicas acordes a la realidad en que vive.

La Funai ha promovido también convenios y apoyos a las licenciaturas interculturales (o sea, a la formación de maestros indígenas de modalidad específica), por considerarlas más adecuadas y pertinentes a la realidad indíge-

\footnotetext{
${ }^{10}$ La Funai ha establecido convenios de cooperación para apoyar a los alumnos indígenas con las siguientes universidades: Universidad de Brasilia, Universidad Federal de Paraná, Pontificia Universidad Católica de São Paulo, Centro Universitario da Grande Dourados, Universidad del Estado de Mato Grosso do Sul, Universidad Católica de Don Bosco y Universidad Federal de Roraima.

${ }^{11}$ Coincido con Paulino cuando afirma que la condición para recibir algún beneficio a cambio de un supuesto "compromiso obligatorio" con la comunidad puede reproducir la lógica del privilegio: "si el estudiante está siendo beneficiado, deberá hacer algo para merecerlo, con el desarrollo de proyectos junto a su pueblo como una especie de pago o devolución del beneficio" (Paulino, 2008: 127).
} 
na, para lo cual ha establecido acciones conjuntas con las universidades que las coordinan, garantizando el transporte de los maestros indígenas durante los periodos de curso, la compra del material didáctico y un acompañamiento técnico y pedagógico, entre otros.

Es importante señalar que la asistencia escolar de la población indígena, que inicialmente incumbía a la Funai, ahora es responsabilidad del Ministerio de Educación según el Decreto 026/91 de 1991. La Coordinación General de Apoyo a las Escuelas Indígenas, que formaba parte de la Secretaría de Educación Infantil y Fundamental, fue la primera encargada de ofrecer esta asistencia. Esta Secretaría sólo abarcaba la educación preescolar y de nivel primario, y el hecho de que la educación indígena dependiese de ella reflejaba que el Estado entendía su obligación de garantizar asistencia escolar a los pueblos indígenas apenas en sus niveles más básicos. Sólo hasta 2003, un decreto ministerial estableció, en el ámbito de la Secretaría de Educación Superior (SESU), la responsabilidad de la elaboración de una política para la formación universitaria de los pueblos indígenas (Souza, 2003: 33).

A partir de presiones originadas en el plano internacional, de intelectuales, ONG y movimientos sociales como el de los negros e indígenas, el Ministerio de Educación, a fines del segundo mandato del presidente Fernando Henrique Cardoso, creó un programa para la inclusión en la universidad de poblaciones víctimas de discriminación racial ${ }^{12}$. Éste fue instituido por medio de la Ley 10.558, del 13 de noviembre de 2002, y se llamó Programa Diversidad en la Universidad. Acceso a la Universidad de Grupos Socialmente Desfavorecidos. Fue coordinado por la Secretaría de Educación Media y Tecnológica y

\footnotetext{
${ }^{12}$ En ese entonces, negros e indígenas, y también otros segmentos reconocidos por vivir en condiciones de vulnerabilidad social, estaban prácticamente excluidos de la universidad. Diversos estudios muestran que la mayoría de los alumnos universitarios en Brasil se identificaban como blancos, de clase media y urbana, y provenían de escuelas de buen nivel. Por ejemplo, Carvalho y Segato constataron, basándose en el censo de 2002 del Instituto Nacional de Estudios e Investigaciones Educativas (Instituto Nacional de Estudos e Pesquisas Educacionais, INEP) —cuando aún eran pocas las universidades que habían implementado acciones afirmativas para la inclusión de negros e indígenas - que $97 \%$ de los estudiantes universitarios brasileños se consideraban blancos, $2 \%$ negros y $1 \%$ amarillos (Carvalho y Segato, 2002).
}

financiado con recursos del Banco Interamericano de Desarrollo ${ }^{13}$. Los objetivos del Programa eran financiar y fortalecer cursos que ya venían funcionando bajo la coordinación de diferentes entidades de la sociedad civil, destinados a la preparación de población afrodescendiente y de bajos recursos para el examen de ingreso universitario; y financiar y estimular la realización de estudios e investigaciones para subsidiar la formulación de políticas de inclusión social en la educación superior ${ }^{14}$.

Durante el gobierno de Fernando Henrique Cardoso, el ministro de Educación, Paulo Renato de Souza, opinaba que la solución al desfase educativo de negros e indígenas debía ser combatido con políticas dirigidas a mejorar la educación pública en su conjunto. No obstante, se le urgió a que diera respuesta a algunas de las cuestiones planteadas en la Conferencia Mundial contra el Racismo, la Discriminación Racial, la Xenofobia y las Formas Conexas de Intolerancia, de la Organización de las Naciones Unidas (ONU) realizada en septiembre de 2001, en Durban, Sudáfrica, ya que Brasil había suscrito el Programa de Acción y la Declaración resultantes de la Conferencia. En estos documentos se recomendaba a los Estados participantes que adoptasen políticas de acción afirmativa para las poblaciones víctimas de discriminación y de prejuicios étnico-raciales, para garantizar el acceso de las mismas a los servicios básicos, como educación, salud, habitación, etc. (Almeida, 2008). Como el ministro de Educación se oponía a implementar reservas de cuotas como modalidad para garantizar el ingreso de esa población a la universidad, y frente a la necesidad de responder a los compromisos resultantes de la Conferencia, decidió crear un programa que brindara apoyo financiero y estimulase la acción de entidades que tuviesen experiencia en la organización y dictado de cursos preparatorios para el ingreso a la universidad dirigidos a población negra e indígena. En Brasil, estos cursos son llamados "pre-vestibulares" y el examen de ingreso a las instituciones de educación superior, "vestibulares". Los cursos de preparación son llevados a cabo por diversas instituciones educativas y por lo general son muy caros. Sin embargo, entidades de la sociedad civil y grupos vinculados con la Iglesia católica han organizado, hace varios años, cursos dirigidos a población de bajos recursos. Con el Programa Diversidad en la Universidad se intentó beneficiar a estos cursos y estimular la proliferación de otros, en vista de que la población excluida de la universidad mejorase su desempeño y pudiese aprobar los exámenes de admisión a las universidades públicas.

${ }^{13}$ Véase Almeida (2008) para un análisis más profundo del Programa Diversidad en la Universidad. En línea: <http://www.trilhasdeconhecimentos.etc.br/dissertacoes_teses/arquivos/Disserta $\%$ E7\%E3oNinaPaivaAlmeida.pdf? codArquivo $=129>$.

${ }^{14}$ Cabe destacar que el Programa Diversidad en la Universidad benefició principalmente a la población afrodescendiente. En la convocatoria abierta sólo fueron apoyadas dos instituciones que ofrecían cursos de preparación exclusivamente para indígenas: la Universidad del Estado de Mato Grosso do Sul (UEMS) y el Centro Universitario de Grande Dourados (Unigran). También se financiaron dos experiencias piloto de cursos especialmente ideados para población indígena, que atendían especificidades concretas, llevados a cabo por dos ONG de apoyo al indio en zonas indígenas. Estos proyectos piloto no fueron escogidos por convocatoria pública, sino indicados por la Coordinación General de Apoyo a las Escuelas Indígenas del MEC. De igual forma, el otro componente que formaba parte del programa 
El Programa, ideado a fines del gobierno del presidente Cardoso, tuvo que ser aplicado en su mayor parte durante el primer mandato de gobierno de Luiz Inácio Lula da Silva. A partir de la reestructuración que sufrió el Ministerio de Educación durante la gestión del segundo mandato de Lula, el Programa fue trasladado a la entonces recién creada Secretaría de Educación Continua, Alfabetización y Diversidad (SECAD). No obstante, en el transcurso de ese periodo, el apoyo a los cursos de preparación para el ingreso universitario fue perdiendo fuerza en la agenda política del Ministerio de Educación, ya que la nueva política apuntó a estimular — como forma de acción afirmativa - la implementación en las universidades de "sistemas de cuotas". Ésta es la forma más común de referirse a las diversas modalidades que las instituciones universitarias crean para reservar un cierto porcentaje de vacantes para los segmentos de la población históricamente excluida de este nivel educativo (afrodescendientes, indígenas, alumnos de bajos recursos socioeconómicos, alumnos provenientes de escuelas públicas, alumnos con deficiencias físicas, entre otros). El a nivel nacional, sino de la acción de algunos estados que han sancionado leyes que obligan a las universidades bajo su jurisdicción a implementar acciones afirmativas en su modalidad de ingreso. Asimismo, algunas universidades nacionales también han puesto en práctica estas medidas a partir de la deliberación y resolución de sus Consejos Superiores.

Es importante mencionar que tanto en el ámbito intelectual como en los medios de comunicación se produjo un intenso y acalorado debate en torno a las acciones afirmativas en el país, aunque la discusión se restringió al tema del sistema de cuotas y a posicionarse a favor o en contra del mismo, sin análisis más profundos o contribuciones que trascendieran esta controversia (Santos, 2005; Souza Lima, 2007). La cuestión que más levantó polémica fue que las acciones afirmativas tuvieran un criterio étnico-racial. Un sector vinculado al ámbito académico

-la elaboración de estudios e investigaciones- estuvo mayormente dirigido a la población negra y coordinado por intelectuales del movimiento negro. argumentó contra la implementación de una política social basada en una clasificación racial que no existe desde un punto de vista científico, afirmó que con esta medida se legitimaba el concepto de raza (Maio y Santos, 2006). También criticó el hecho de que la población destinataria de tal política debiese optar por categorías rígidas, ya que para estos intelectuales Brasil era el país del mestizaje y de las infinitas gradaciones de color (Steil, 2006). Las acciones afirmativas para indígenas — tal vez por el hecho de ser percibidos éstos como un segmento numéricamente insignificante de la población brasileñano suscitaron tanta polémica como la que se produjo respecto de los negros o afrodescendientes, salvo en las universidades localizadas en lugares en que las relaciones entre la población indígena y no indígena son muy conflictivas, como es el caso de los estados de Mato Grosso do Sul y Roraima.

Durante el primer mandato del presidente Lula da Silva, en el contexto de reestructuraciones y cambios que se produjeron en el Ministerio de Educación, destaca la creación, en julio de 2004, de la SECAD, a la que se aludió líneas arriba, como resultado de una política de reconocimiento a la diversidad por parte del Ministerio de Educación. Esta Secretaría surgió para coordinar la educación de jóvenes y adultos, la educación rural, la educación ambiental, la educación escolar indígena y la educación para la diversidad étnico-racial, cuestiones que estaban dispersas en otras secretarías ${ }^{15}$.

En paralelo a la creación de la SECAD fueron implementadas nuevas acciones, como el Programa Universidad para Todos (PROUNI), coordinado por la Secretaría de Educación Superior, que prevé la concesión de becas a alumnos de bajos recursos socioeconómicos que estudian en universidades privadas - las cuales, como dije antes, por tener procesos de selección menos competitivos que las públicas son de más fácil acceso para los que no

\footnotetext{
${ }^{15}$ La Coordinación General de Apoyo a las Escuelas Indígenas, que había sido la responsable de coordinar las acciones a nivel nacional relativas a la educación escolar indígena, actuó hasta julio de 2004, cuando, por medio del Decreto Presidencial número 5.159/2004, fue transformada en Coordinación General de Educación Escolar Indígena, vinculada al Departamento de Educación para la Diversidad y la Ciudadanía de la SECAD.
} 


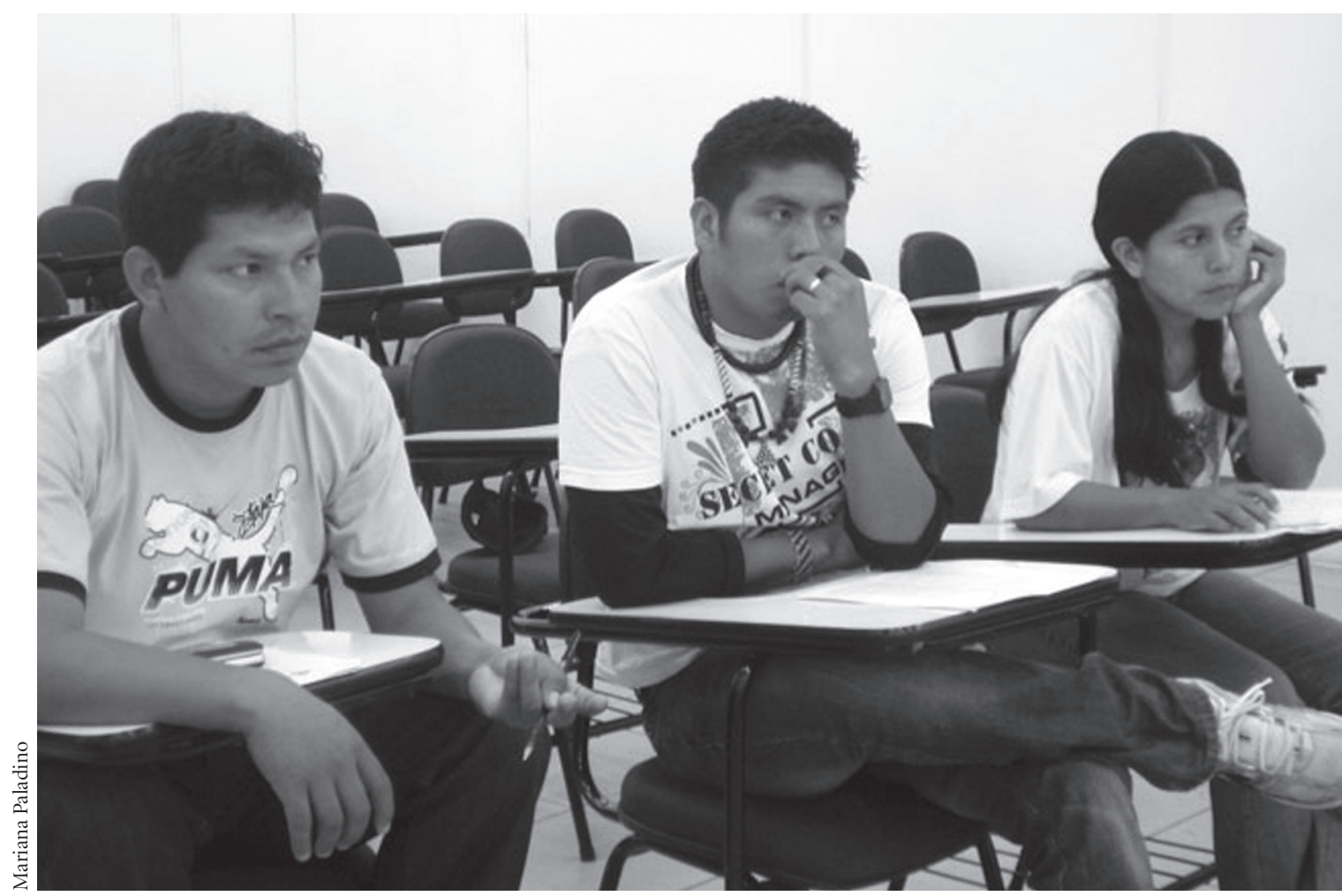

Estudiantes indígenas de Mato Grosso do Sul en el Programa de Permanencia Rede de Saberes, desarrollado por la Universidad Estatal de Mato Grosso do Sul, la Universidad Católica Don Bosco, la Universidad Federal de Mato Grosso do Sul y la Universidad Federal de Grande Dourados, financiado por la Fundación Ford.

han podido recibir una educación de calidad en los niveles previos al superior- Entre los beneficiados por este Programa se incluye un porcentaje determinado, según la región, para negros e indígenas. Sin embargo, en lo que respecta a la inclusión de indígenas, varios estudiantes entrevistados dan cuenta de que no ha sido fácil tener acceso a este programa, tanto por la falta de divulgación como por el desconocimiento de las gestiones burocrático-administrativas que requiere la solicitud de la beca.

En 2005 se puso en marcha el Programa de Apoyo a la Formación Superior y a las Licenciaturas Indígenas (PROLIND), como una acción gubernamental de fomento a la educación superior indígena, destinada en especial a garantizar la creación, implantación y desarrollo de las licenciaturas interculturales para la formación de maestros indígenas y a poder ajustarse al Plan Nacional de Educa- ción, que prevé el ejercicio del magisterio para los que tienen un título de nivel superior. Este Programa fue y es implementado por la SECAD, en articulación con la SESU, y contó en su periodo inicial con recursos del Programa Diversidad en la Universidad, mencionado anteriormente.

El PROLIND se estructuró bajo la forma de una convocatoria abierta a las universidades y estaba orientado a financiar, en sus comienzos, tres tipos de acciones: las licenciaturas interculturales indígenas ya existentes o en vías de ser implantadas, la elaboración y planificación de nuevas licenciaturas para la formación de maestros indígenas, y el incentivo para que los alumnos indígenas que estudian en las carreras comunes de las universidades públicas se inserten en proyectos de investigación y estudios, bajo la supervisión de docentes, como una medida para estimular su permanencia (Souza Lima, 2008). Sin em- 
bargo, el Programa dejó de apoyar esta tercera acción y sólo se dirige a la creación de nuevas licenciaturas interculturales o a la continuidad y el desarrollo de las que ya existen. En la actualidad, se implementan licenciaturas interculturales para indígenas en trece universidades públicas: nueve de ellas se desarrollan en universidades federales ${ }^{16} \mathrm{y}$ cuatro en universidades de nivel provincial ${ }^{17}$.

El hecho de que se eliminase del PROLIND la acción destinada a fomentar la permanencia de los alumnos indígenas en las universidades públicas refleja el desinterés por implementar una política de educación superior para la población indígena de forma consistente y que apunte no sólo a su inclusión, sino también a evitar su desgranamiento.

Para finalizar este recorrido por las políticas gubernamentales dirigidas directa o indirectamente a promover la educación superior indígena, cabe mencionar la implementación de un programa de expansión de la educación superior pública que está en curso, en el marco del cual el Estado estimula la adopción, por parte de las universidades federales, de políticas para el aumento de su alumnado, entre ellas las acciones afirmativas. Se trata del pansión de las Universidades Federales (REUNI), creado a partir del Decreto 6.096/2007, vinculado con el Plan de Desarrollo de la Educación (PDE) del actual gobierno de Lula.

A partir de la síntesis anterior, podemos concluir que las principales acciones que el gobierno ha privilegiado hasta ahora en relación con la educación superior indígena son: por un lado, la formación de maestros indígenas bajo la modalidad de las licenciaturas interculturales (a través del PROLIND) y, por el otro, el ingreso de indígenas a carreras universitarias de modalidad no específica, sea estimulando a las instituciones públicas para que implementen sistemas de cuotas, sea ofreciendo becas para el pago de las colegiaturas en las instituciones privadas (a través del PROUNI). Se trata de políticas que privilegian

\footnotetext{
${ }^{16}$ Roraima, Minas Gerais, Grande Dourados, Goiás, Tocantins, Amapá, Amazonas, Acre, Campina Grande.

${ }^{17}$ Universidad del Estado de Mato Grosso, Universidad del Estado de Amazonas, Universidad del Estado de Bahía y Universidad de São Paulo.
}

el ingreso a la educación superior, pues el gobierno no ha elaborado una política a nivel nacional que promueva la permanencia de los alumnos indígenas en las universidades públicas ${ }^{18}$. Tampoco ha promovido acciones para la creación de cursos y carreras específicas destinadas a la población indígena en áreas diferentes de la formación pedagógica, ni ha insistido en la transformación curricular de las carreras tradicionales para que se adecúen a la diversidad del alumnado. Esta omisión es grave si consideramos que forma parte de las preocupaciones y demandas importantes de los estudiantes indígenas, como veremos más adelante.

\section{Breve recorrido por las acciones afirmativas implementadas por las universidades públicas brasileñas}

Hasta 2008 había 43 instituciones de enseñanza superior que presentaban formas de acción afirmativa para el acceso de alumnos indígenas: 28 de ellas estatales y 15 federales (universidades nacionales) ${ }^{19}$. Considerando la distribución regional de estas universidades, se verifica que siete se ubican en la región nordeste del país, tres en la región norte, 17 en la región sudeste, cuatro en la región centro-oeste y 12 en la región sur. Cabe destacar que no hay una correlación entre el establecimiento de acciones afirmativas en algunas universidades y la distribu-

\footnotetext{
${ }^{18}$ Según Souza Lima (2008), la sensibilidad gubernamental frente a los problemas indígenas es tenue y objeto de muchas protestas por parte de las organizaciones indígenas que han entregado al gobierno propuestas, manifiestos y otros documentos, además de haber realizado importantes movilizaciones, aunque con resultados no tan positivos. La falta de coordinación de las políticas indígenas reflejó esa poca atención y el equipo encargado de la educación indígena en la SECAD/ MEC, responsable de una acción transversal, se ha visto bastante sobrecargado con tareas que serían de la responsabilidad de la SESU/MEC.

${ }^{19}$ Datos recolectados del estudio realizado por algunos miembros del equipo del proyecto "Trilhas de conhecimentos. O Ensino Superior de Indígenas no Brasil", asociado al Laboratorio de Investigaciones en Etnicidad, Cultura y Desarrollo, Museo Nacional, Universidad Federal de Río de Janeiro. El estudio consistió en identificar instituciones de educación superior públicas que implementasen acciones afirmativas. De 213 instituciones analizadas, se identificaron 43 que desarrollan algún tipo de acción afirmativa. Véase el estudio en detalle en línea: <http://www.trilhasdeconhecimentos.etc.br/educacao_ superior_indigena/index.htm $>$.
} 
ción y cantidad de población indígena en el territorio nacional (Cajueiro, 2008). Es decir, la implementación de acciones afirmativas no se guía por el criterio de que las universidades abarquen las regiones donde hay una cantidad de población indígena significativa. Por ejemplo: en la región norte, que comprende la región amazónica, donde está concentrada la mayor parte de la población indígena del país, sólo $18 \%$ de las instituciones de educación superior realizan acciones afirmativas. Al contrario, en la región sur, donde se encuentra la menor presencia poblacional indígena de Brasil - $11.5 \%$ $34 \%$ de las instituciones de educación superior establecieron acciones afirmativas, lo que la convierte en la región brasileña con mayor diseminación de este tipo de políticas (Cajueiro, 2008) ${ }^{20}$.

En relación con los mecanismos de selección de los candidatos indígenas, se observa que $28 \%$ de esas 43 instituciones realizan exámenes de ingreso específicos para los candidatos indígenas. Es decir, con criterios de selección y contenidos diferenciados respecto del de los otros candidatos ${ }^{21}$. Las demás los someten al examen de ingreso convencional, pero después, según sea la modalidad de acción afirmativa que implementen, los candidatos indígenas acceden a través de reserva de vacantes, vacantes suplemen-

\footnotetext{
${ }^{20}$ Las acciones afirmativas destinadas al ingreso de alumnos indígenas a la universidad tienen diversas modalidades. Una es lo que se llama "reserva de lugares o vacantes", es decir, la universidad establece, en consonancia con el total de vacantes disponibles para el ingreso de alumnos en cada carrera, un porcentaje reservado a los indígenas. Otra es la creación de "vacantes suplementarias", es decir, que se abren nuevos lugares para este rango de la población, por lo cual los beneficiados que ingresan por medio de cuotas no ocupan las vacantes de los que ingresan por medio del examen de ingreso convencional. Por tal motivo, esta modalidad es menos cuestionada. Por último, existe la modalidad de "agregar puntaje", o sea, el alumno indígena es sometido al examen habitual, pero al resultado que obtiene se le agrega una cantidad determinada de puntaje. De las 43 instituciones de educación superior que implementan acciones afirmativas, poco más de $50 \%$ optaron por reserva de vacantes y casi $40 \%$ por vacantes suplementarias.

21 Todas las universidades que realizan exámenes específicos como mecanismo de selección de los candidatos indígenas - excepto la Universidad Federal de Roraima - optaron por definir como modalidad de implementación de las acciones afirmativas la creación de vacantes suplementarias. Es decir, esos alumnos ocupan lugares especialmente creados para ellos, por lo que no cubren las vacantes disponibles para los alumnos que ingresan por medio del examen de ingreso convencional (Cajueiro, 2008).
}

tarias o agregación de puntaje $\mathrm{e}^{22}$. Estas acciones, que apuntan al ingreso de alumnos indígenas a la universidad y que en general son bastante recientes, no siempre van acompañadas de políticas destinadas a garantizar la permanencia y el buen desempeño de los mismos.

Es evidente que las situaciones son muy diversas y que cada una merecería un trabajo individual ${ }^{23}$. Algunas universidades que implementan en la actualidad acciones afirmativas ya tenían — a través de grupos de investigación, núcleos o departamentos- antiguas relaciones de vinculación —académica y política- con grupos indígenas y, por lo tanto, las experiencias desarrolladas con alumnos de esos pueblos se sustentan en un conocimiento previo y en la escucha de las necesidades planteadas por estudiantes, líderes y organizaciones indígenas. Otras universidades comenzaron a tener ese contacto solamente a partir de la acción afirmativa, y en muchos casos existe poca preparación y conocimiento de la realidad indígena y de cómo implementar políticas y acciones que sean participativas y pertinentes por parte de los gestores y profesores universitarios.

Cabe destacar también que, en varias universidades, las políticas de apoyo a la permanencia de los alumnos indígenas se han definido años después de implementarse las políticas de acceso. Es el caso de las universidades del estado de Paraná, donde la Ley 13.134 que sancionó cuotas para indígenas se remonta al año 2001, pero sólo hasta el 27 de diciembre de 2007 se complementó con la Ley 15.759, la cual establece que la Secretaría de Ciencia, Tecnología y Educación Superior de Paraná deberá garantizar becas a los estudiantes indígenas (Paulino, 2008). En general, las acciones de permanencia son planeadas y desarrolladas por iniciativa de las propias universidades, en convenios y acuerdos con diversos organismos. Se trata de proyectos

\footnotetext{
${ }^{22}$ Véase nota 20 para una explicación de esas tres modalidades. ${ }^{23}$ Véase Repetto (2008) y Repetto, Neves y Fernandes (2008) para un análisis de las acciones de apoyo a la educación superior indígena desarrolladas por la Universidad Federal de Roraima; véase Cordeiro (2007) y Nascimento y Urquiza (2008), para conocer las acciones afirmativas de las universidades de Mato Grosso do Sul, y Paulino (2008) para un análisis de las acciones afirmativas para indígenas implementadas en las universidades provinciales y federal de Paraná. Varios de estos trabajos están disponibles en línea, en la página web: $<$ www.trilhasdeconhecimentos.etc.br $>$.
} 


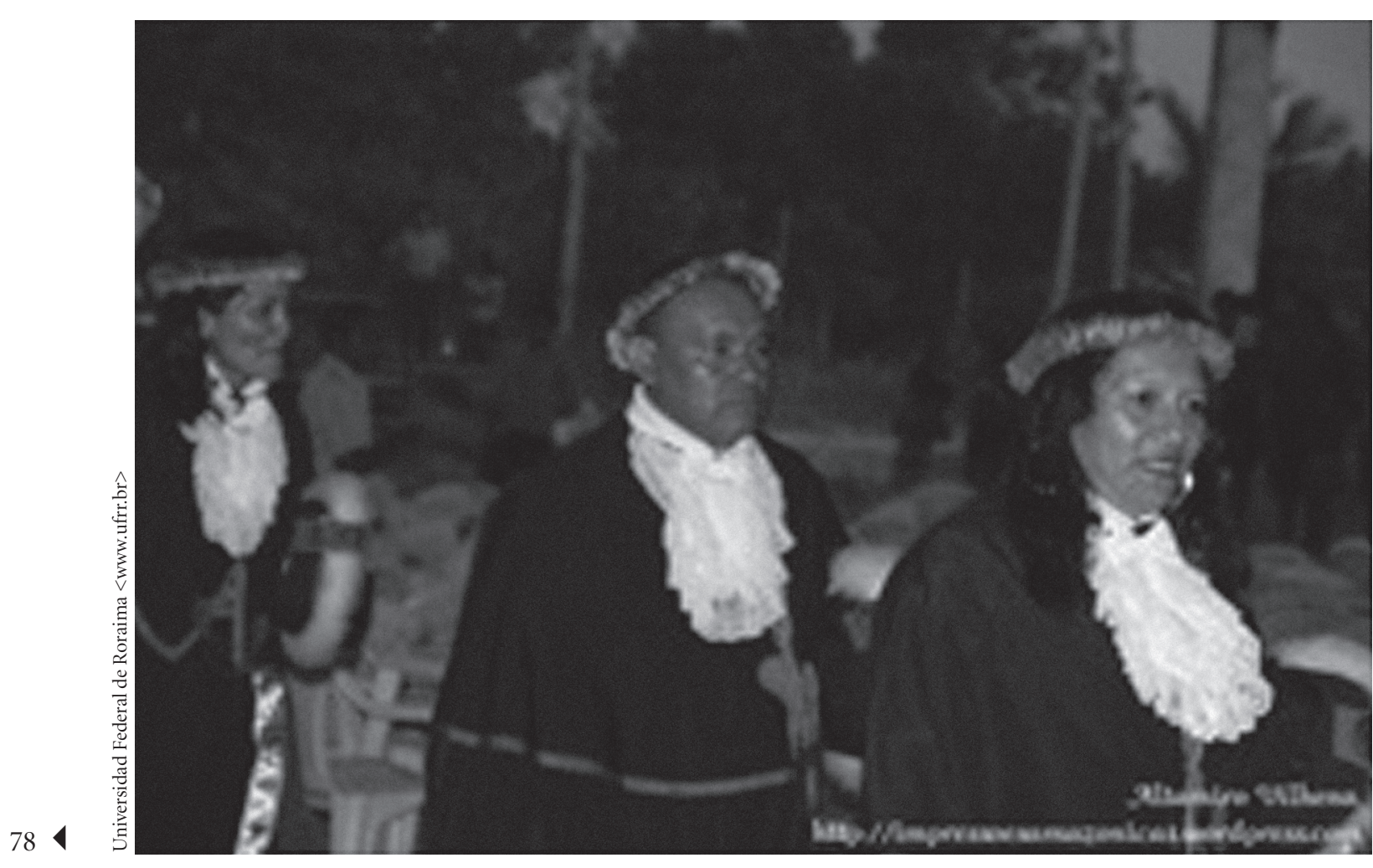

Celebración de la entrega de títulos al primer grupo de maestros indígenas graduado en la Licenciatura Intercultural, coordinada por la Universidad Federal de Roraima. Se graduaron 38 alumnos de las etnias macuxi, yekuana, wapichana, ingarikó, taurepang y wai wai.

o programas que, sobre todo, apuntan al apoyo económico para los alumnos indígenas.

Varios actores involucrados - sobre todo los estudiantes- llaman la atención sobre la precariedad e insuficiencia de tales acciones para resolver las problemáticas y necesidades específicas de los alumnos indígenas. Por ejemplo, los auxilios económicos que otorga la Funai o los gobiernos locales en algunos estados no contemplan el hecho de que muchos de ellos sean casados y con hijos, y que el dinero recibido será destinado también a su manutención. Los montos de las becas son insuficientes para mantener el patrón de vida de un estudiante universitario que no cuenta con casa propia en la ciudad donde estudia, y más aún para el que tiene una familia que sustentar. Aún hay poca comprensión por parte del gobierno y de las universidades de que las acciones afirmativas para los indígenas deberían asumir características distintas a las aplicadas a las otras poblaciones destinatarias de tales políticas (negra o afrodescendiente, población de bajos recursos económicos, etc.). Como plantea Souza Lima (2007), no es lo mismo instituir una política orientada a la garantía de un derecho individual que a la garantía de derechos colectivos a grupos o poblaciones que deciden mantenerse culturalmente diferenciados, como es el caso de los pueblos indígenas.

Las pocas universidades que desarrollan acciones destinadas a la permanencia de los alumnos indígenas desde una perspectiva más amplia, que no reducen la cuestión al apoyo económico, las llevan a cabo en su mayoría con recursos externos a la universidad. Establecen convenios o asociaciones con órganos del gobierno provincial o federal y con agencias no gubernamentales. Estas acciones abarcan tutorías, acompañamiento social y pedagógico, proyectos de investigación y extensión en los que 
involucran a los estudiantes indígenas como investigadores, realización de cursos y eventos que tienen como objetivo visibilizar la presencia de esta población en la universidad y valorizar los conocimientos indígenas, entre otros.

En la intervención y el apoyo financiero a algunos de los programas de permanencia desarrollados en universidades brasileñas para la población afrodescendiente e indígena destaca la actuación de la Fundación Ford ${ }^{24}$ a través del programa Pathways to Higher Education. En lo que respecta al fortalecimiento de las acciones volcadas hacia la población indígena, esta institución financió dos núcleos universitarios que promueven iniciativas destinadas a la educación superior de los indígenas, en particular a su permanencia ${ }^{25}$ por medio del proyecto "Trilhas do conhecimento. O ensino superior indígena no Brasil" 26 . Se trata del Programa Red de Saberes, ejecutado en conjunto por la Universidad Católica Don Bosco, la Universidad del Estado de Mato Grosso do Sul y, de manera más reciente, la Universidad Federal de Mato Grosso do Sul y la Universidad Federal de Grande Dourados ${ }^{27}$, todas ellas localizadas en el estado de Mato Grosso do Sul; y el Programa E'ma Pia, coordinado por el núcleo Insikiran de la Universidad Federal de Roraima, dirijido a indígenas de ese estado ${ }^{28}$.

\footnotetext{
${ }^{24}$ La Fundación Ford fue pionera en el desarrollo de proyectos vinculados con la promoción de la diversidad en la educación, pues incluyó entre sus líneas de acción la perspectiva de "combate a las desigualdades raciales en la educación" desde la década de 1980 y, con más fuerza aún, a partir de mediados de la década de 1990 (Almeida, 2008: 42).

25 También la Fundación Ford, a través del International Fellowship Program (IFP) ofrece en Brasil, desde el año 2002, becas de posgrado — 40 becas anuales para maestría o doctorado- para hombres y mujeres con potencial de liderazgo en sus campos de actuación, para que puedan proseguir sus estudios, dándole prioridad a candidatos provenientes de grupos que han tenido un acceso restringido a la educación superior. De las 170 becas ya concedidas en Brasil, 12 fueron para indígenas.

26 "Sendas de conocimientos. La educación superior indígena en Brasil". Véase sobre este proyecto a Souza Lima (2008) y en línea la página web $<$ trilhasdeconhecimentos.etc.br $>$

27 Para más informaciones sobre este programa véase en línea: $<$ www.rededesaberes.org $>$.

${ }^{28}$ Para más información sobre el núcleo Insikiran y el Programa E'ma Pia, véase en línea: <http://www.insikiran.ufrr.br/emapia.
} htm>.

\section{LOS ESTUDIANTES UNIVERSITARIOS INDÍGENAS. DATOS PRELIMINARES PARA UN DIAGNÓSTICO DE SU SITUACIÓN Y SUS DEMANDAS}

En la actualidad se estima una presencia de cerca de 5000 estudiantes indígenas en la educación superior en Brasil (CEB/CNE, 2007, apud Luciano, 2009), incluyendo a los que realizan las licenciaturas interculturales indígenas, que llegan a casi 1 500. Luciano (2006) llama la atención sobre este crecimiento acelerado, recordando que hasta hace una década la cantidad de estudiantes en la educación superior no alcanzaba los 500. Este fenómeno refleja el impacto de las políticas de acción afirmativa, principalmente de la política de cuotas. Ocurre lo contrario en el nivel de educación secundaria, donde no hubo un crecimiento equivalente en la oferta escolar, debido a la poca sensibilidad y voluntad política de los sistemas provinciales y municipales responsables de coordinar este nivel de enseñanza.

Es importante destacar que las universidades conocían muy poco sobre los destinatarios de sus acciones afirmativas. Varias instituciones, a partir del reconocimiento de este vacío, han comenzado a realizar diagnósticos sobre el perfil de los indígenas. Algunos de estos estudios son resultados de trabajos en equipo y de investigación. También la organización indígena Centro Indígena de Estudios e Investigaciones (CINEP) ${ }^{29}$ realizó un estudio durante los años 2007 y 2008 para poder construir un diagnóstico sobre la situación del estudiante indígena universitario ${ }^{30}$.

${ }^{29}$ Es una organización indígena creada en 2005 por líderes, estudiantes e investigadores indígenas con el propósito de crear un espacio de referencia para el debate, el apoyo y la asesoría al movimiento indígena brasileño en las múltiples dimensiones políticas, técnicas y académicas sobre las cuales los líderes indígenas precisan dar cuenta en su trabajo y proyectos.

${ }^{30} \mathrm{El}$ diagnóstico fue ideado a partir de la aplicación de un cuestionario con 38 preguntas, que apuntaban a obtener datos socioeconómicos de los estudiantes indígenas universitarios, así como a conocer las dificultades que atraviesan en este nivel educativo. El trabajo abarcó a personas que estudian en la ciudad de Manaos, estado de Amazonas; en la ciudad de Brasilia, capital del país; en la región nordeste de Brasil (estados de Pernambuco y Bahía); en la región sur (estado de Río Grande do Sul) y en la región centro-oeste (estado de Mato Grosso do Sul); en total fue recogida información de 480 estudiantes indígenas universitarios. Me apoyaré en los datos de este es- 
A partir de la lectura y el análisis de algunos de esos registros, pude observar que las características de los estudiantes indígenas, de sus trayectorias y de las situaciones atravesadas en relación con el ingreso y permanencia en la universidad son bastante diversas. Sin embargo, plantearé aquí algunas tendencias o características recurrentes que pude verificar. El estudio registró una mayor cantidad de mujeres que de hombres en la educación superior, aunque esto varía bastante según la región. En el nordeste del país predominan las estudiantes mujeres; en Brasilia, también, pero con una pequeña diferencia en relación con el número de varones. Al contrario, en Mato Grosso do Sul y en las regiones norte y sur del país hay una mayor presencia de hombres que de mujeres en la universidad.

Muchos estudiantes indígenas deben recorrer grandes distancias desde su territorio de origen para tener acceso a una educación superior ${ }^{31}$. Es el caso, sobre todo, de los que estudian en Manaos y Brasilia. En la primera ciudad se registra la presencia de alumnos universitarios procedentes de 14 etnias, todas originarias de la región amazópúblicas. En estas últimas, la mayoría de estudiantes está concentrada en la Universidad del Estado de Amazonas, que implementó —a partir del año 2004— un sistema de cuotas para indígenas. En Brasilia estudian alumnos de 14 etnias, la mayoría provenientes del nordeste del país, que han ingresado a los estudios superiores a partir de un convenio establecido entre la Universidad de Brasilia y la Funai.

Los indígenas de la región sur y nordeste del país, ya sea que estén estudiando o que ya se hayan graduado, trabajan al mismo tiempo, casi todos, como maestros de escuelas ubicadas en comunidades indígenas, y su elección de ingresar en la educación superior debe entenderse, en gran medida, por la necesidad de obtener un título que

tudio - en el cual colaboré con la organización indígena, sistematizandoyanalizandoloscuestionarios-para realizar las observaciones que desarrollaré a continuación.

31 Aunque este movimiento no es una novedad, ya que la mayoría tuvo que trasladarse y migrar a la ciudad —o al menos viajar largas distancias de ida y vuelta cada día - para cursar los últimos años de la escuela primaria y secundaria.

garantice su estabilidad laboral. Hablando en términos genéricos, este segmento vive en la comunidad, estudia en universidades próximas y ya ha constituido su propia familia. Se trata de personas, en un porcentaje considerable, casadas y con hijos, o solteras, pero con hijos.

En el caso de los indígenas que estudian en Manaos y Brasilia ocurre lo contrario, pues en su gran mayoría no son docentes ni se desempeñaban como tales. Eligen carreras en otras áreas de formación, sobre todo en el área de la salud, las ciencias biológicas o agrarias y las ciencias sociales o humanas. Entre ellos aparece un segmento que - a pesar de tener una edad considerada adecuada para tener hijos - ha postergado la formación de una familia propia, con el objetivo de continuar avanzando en su escolarización. Entre los padres de los estudiantes abarcados por el estudio del CINEP, salvo aquellos provenientes de la región norte, donde hay una mayoría dedicada a la agricultura de subsistencia, existe una cantidad considerable que se desempeña en trabajos asalariados o en cargos de cierto estatus, como el de maestro, agente sanitario, funcionario de la Funai, entre otros.

Los estudiantes de la región norte se mantienen en Manaos gracias al apoyo económico que reciben de su familia o con los sueldos que ganan en sus trabajos. La mayoría está empleada en órganos públicos del gobierno municipal y provincial, vinculados a políticas indigenistas. Ninguno de ellos recibe beca de la Funai. En la región sur y nordeste, la gran mayoría se mantiene con su sueldo de maestro. Los que estudian en Brasilia lo hacen gracias al auxilio financiero de la Funai ${ }^{32}$. En Mato Grosso do Sul, algunos reciben becas del gobierno del estado y otros tienen un empleo.

La elección de carreras es variada en todas las regiones, aunque se evidencia que en gran medida está orientada por las opciones disponibles. Prueba de esto es que en las universidades que implementan sistemas de cuotas en todas las carreras, como ocurre en la Universidad del Es-

\footnotetext{
32 También los que cursan carreras vinculadas con el área de salud reciben becas del proyecto llamado Vigisus, dependiente de la Fundación Nacional de la Salud, cuyo objetivo es apoyar a estudiantes indígenas que se estén formando en medicina, enfermería y odontología.
} 
tado de Amazonas o en la Universidad del Estado de Mato Grosso do Sul, la diversidad de elección es mayor. En la primera, la matrícula se concentra sobre todo en las carreras de administración, enfermería, filosofía y derecho; en la segunda, las preferidas son pedagogía, enfermería y derecho. En la región sur, la mayoría de los estudiantes cursa las carreras de agronomía, pedagogía, educación física, ciencias biológicas y enfermería; y en la región nordeste, las carreras de pedagogía, historia, letras y geografía. En general, en estas dos últimas regiones, por el hecho de que la mayoría de los que han ingresado en la educación superior se desempeña al mismo tiempo como profesor de escuelas en áreas indígenas, las elecciones están orientadas a carreras que contribuyan a su titulación. También por el hecho de no poder ausentarse de su trabajo, la mayoría escoge las ofertas disponibles de carreras de modalidad semipresencial o a distancia y en universidades localizadas lo más cerca posible de sus aldeas, para no tener la necesidad de radicar en la ciudad. De manera general, los estudiantes comprendidos por el estudio explicaron que la elección por una determinada carrera estuvo motivada tanto por la carencia de profesionales en su comunidad, la necesidad que ésta tiene en esa área y su expectativa de poder contribuir en ese ámbito, como por la posibilidad de conseguir empleo.

En lo que respecta a las dificultades enfrentadas durante los estudios de nivel superior, la mayoría enfatizó en las de tipo económico y de distancia cultural. La manutención en la ciudad fue colocada como un problema en casi todos los casos. Mucho más en los estudiantes que provienen de comunidades y no cuentan con familia en la ciudad, pero incluso para los urbanos es difícil conseguir recursos para el pago del transporte, la alimentación en la universidad, la compra de material didáctico y de los textos, así como el hecho de tener que conciliar estudio y trabajo. También fueron enfatizadas las dificultades en la comunicación con docentes y compañeros no indígenas, ya sea por no compartir ciertos códigos lingüísticos o a causa de los estereotipos y prejuicios que éstos tienen hacia ellos. Muchos de los indígenas llegan a la universidad dominando poco el portugués o la modalidad de lenguaje utilizada en el espacio universitario, y en general hay poco conocimiento y sensibilidad por parte de los profesores

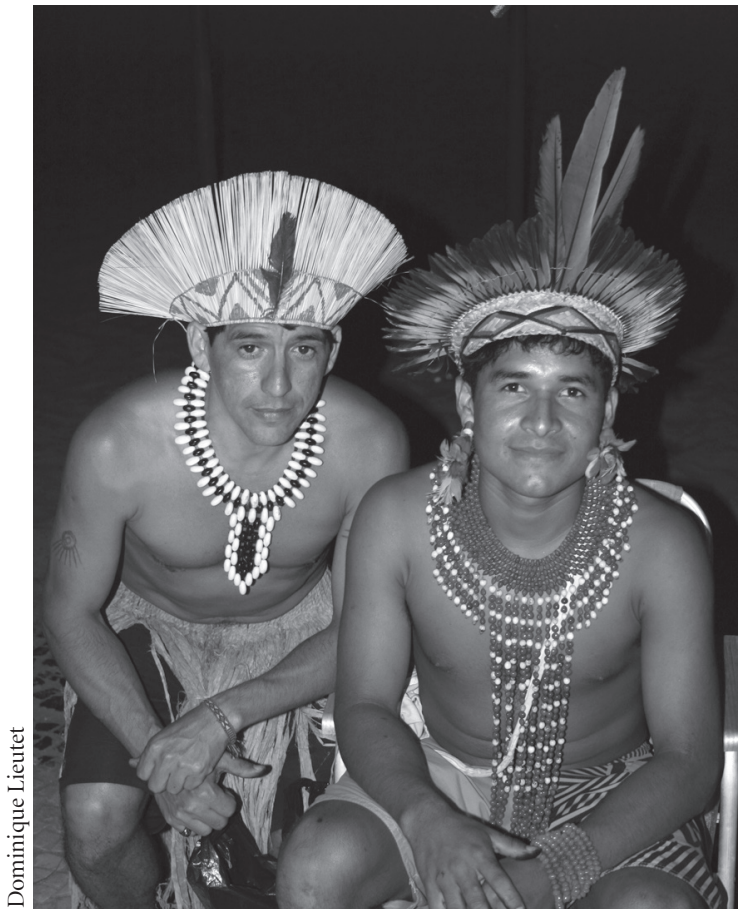

Arassari, 2009

frente a esta situación. Otro de los problemas que mencionan es el desconocimiento de la institución y sus procedimientos administrativo-burocráticos. También señalan la dificultad de seguir los ritmos y formas de enseñanza vigentes en este espacio, así como las técnicas de estudio y formas de conocimiento que, en muchos casos, se oponen a las recibidas durante su socialización primaria en el seno de su grupo de parentesco. Entre las demandas más recurrentes para enfrentar estas dificultades, mencionan la necesidad de que el gobierno elabore programas consistentes enfocados al apoyo económico de los alumnos indígenas, que proporcionen un financiamiento continuo y adecuado a sus necesidades para garantizar su manutención. Existe también una demanda de ampliación de la oferta y la política de cuotas en todas las universidades públicas, así como de expansión de la política de interiorización de las universidades —es decir, que se creen más centros y facultades en el interior del país - para no tener la necesidad de trasladarse a ciudades tan distantes del lugar de origen. También predomina la demanda a las 


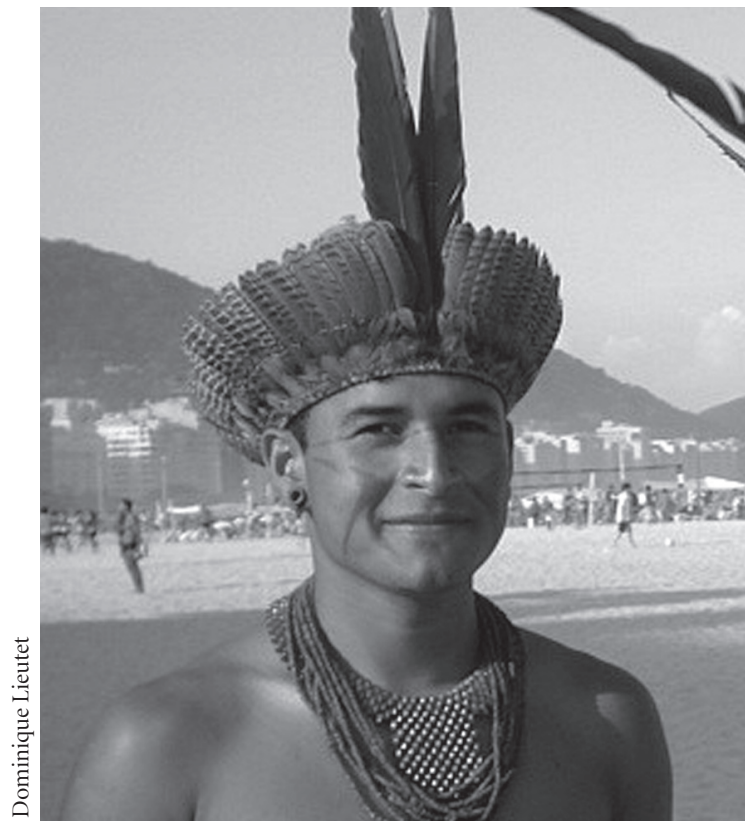

En la playa de Copacabana, 2009.

universidades para que creen núcleos de apoyo para los alumnos indígenas, que puedan acompañarlos de una forma calificada en términos pedagógicos, culturales, políticos y sociales para garantizar su permanencia y buen desempeño en la educación superior. Cabe mencionar la demanda dirigida hacia el propio movimiento indígena, en el sentido de que las organizaciones se comprometan en el acompañamiento y apoyo a los estudiantes indígenas universitarios, al orientarlos y fortalecerlos para enfrentar problemas cotidianos y ayudarlos a pensar en estrategias para mejorar su situación.

\section{A MODO DE CONCLUSIÓN}

Para finalizar, quisiera llamar la atención sobre algunas cuestiones que aparecen de manera recurrente en los espacios de deliberación referidos a la educación superior indígena, como encuentros, seminarios y congresos, que se han desarrollado en los últimos años y que en mi opinión establecen agendas fijas y barreras al abordaje de otros temas.
Una de las cuestiones debatidas gira alrededor de la discusión sobre cuál es la modalidad educativa más pertinente para la formación superior de los pueblos indígenas, si las licenciaturas interculturales de modalidad específica o las carreras comunes. Impera un discurso en el cual se contraponen ambos tipos de formación. Hay cierto consenso acerca de que la modalidad específica es más pertinente a la realidad indígena, promueve la transversalidad y el diálogo de conocimientos, y forma profesionales comprometidos con el etnodesarrollo y el bienestar de su comunidad. En oposición, se piensa en la educación universitaria tradicional como cientificista, dogmática y monocultural, y formadora de profesionales individualistas. Esta forma de concebir dicotómicamente las modalidades de educación superior responde a diferentes posiciones políticas en el campo indigenista (que involucra a la academia, a gestores de políticas públicas, miembros de ONG, y líderes e integrantes de organizaciones indígenas). Sin embargo, hay pocos estudios que analicen cuáles son los significados concretos que los estudiantes indígenas les dan a ambos tipos de formación, de qué forma experimentan y transitan por ellos, qué impactos tienen en sus vidas y en su inserción posterior como profesionales y miembros de su comunidad. Tampoco hay información consistente sobre la forma en que los alumnos lidian con los conocimientos recibidos en la universidad, conocimientos que muchas veces deslegitiman, niegan u ocultan los saberes indígenas, o cómo enfrentan la invisilibidad a la que son sometidos en el espacio universitario o la negación de su identidad como indígenas por el hecho de no responder a los estereotipos comunes que los ubican como seres distantes que están en la selva.

Éstas son algunas de las preguntas que surgen en relación con los posibles impactos de la formación universitaria tradicional (no diferenciada) en los alumnos indígenas, y sobre los cuales hay poca información. Los diagnósticos realizados por algunos programas o núcleos de investigación dentro de las universidades que aplican políticas de acción afirmativa se han canalizado a obtener información acerca de las dificultades, sobre todo económicas, que atraviesan los estudiantes indígenas, pero no recogen suficiente información sobre otros asuntos. Por otro lado, en lo que se refiere a las licenciaturas intercul- 
turales, aunque para muchos sean la opción más deseable y pertinente a la realidad indígena, de hecho hay poca divulgación y conocimiento de los procesos de enseñanzaaprendizaje desarrollados en el interior de las mismas, de qué manera en concreto se elabora la interculturalidad y se coloca en práctica el diálogo de conocimientos. No existen estudios emprendidos desde una perspectiva etnográfica que den cuenta de ello. Lo que se divulga son relatos de experiencias o informes dirigidos principalmente a las agencias de financiamiento $y$, tal vez por el tipo de interlocutores a los que están destinados, se omite en ellos el análisis de las ambigüedades y tensiones presentes en esta modalidad educativa. Es importante aclarar que se está comenzando a realizar experiencias de intercambio y trabajos en conjunto entre licenciaturas interculturales y disciplinas o cursos de las carreras comunes, aunque aún es fuerte la separación.

Otra de las discusiones recurrentes sobre la educación superior indígena gira en torno a la relación deseable entre conocimientos tradicionales y científicos. Hay un consenso sobre la relevancia política, pedagógica y social de la incorporación de conocimientos indígenas en las carreras universitarias y sus propuestas curriculares. Sin embargo, aún hay poco debate sobre las formas de llevarlo a la práctica y evitar los riesgos de su descontextualización, vulgarización y folclorización, en el caso de que no sean aplicados desde perspectivas críticas y descolonizadoras del saber. También hay escasa discusión sobre el tipo de formación y competencias que los profesores universitarios deberían tener para propiciar un diálogo intercultural.

El aporte de la educación superior a las luchas y demandas indígenas y el retorno a la comunidad son otros de los temas siempre aludidos. La comunidad es abordada como un todo coherente y homogéneo que expresaría una unicidad de expectativas e intereses. Algunos estudiantes dan cuenta de ciertas tensiones en esta premisa. Si bien los líderes de sus aldeas emiten un discurso a favor de la importancia de la educación superior y apoyan sus estudios, en la práctica los acompañan poco y viven con cierta desconfianza la formación que reciben y el papel que desarrollarán al graduarse. Los jóvenes reclaman ser más escuchados por los líderes de sus comunidades. A su vez, éstos suelen protestar por lo que consideran una escasa participación de los jóvenes en las organizaciones y poco compromiso con la comunidad. Se evidencian disputas generacionales por el liderazgo y la ocupación de cargos. Además hay poca información acerca de la manera en que se produce el retorno a la comunidad de los estudiantes indígenas universitarios al concluir su formación, cómo se reorganizan las jerarquías internas a su llegada y cómo se insertan en el mercado de trabajo local o extralocal.

Éstas son apenas algunas de las cuestiones que forman parte hoy de las discusiones presentes en el ámbito indígena e indigenista acerca de la educación superior indígena, desarrolladas muy brevemente aquí, pero con la intención de llamar la atención sobre el hecho de que se están convirtiendo en premisas recurrentes y compartidas de un discurso que pareciera no querer avanzar hacia el análisis de las contradicciones, las ambigüedades y los conflictos que toda acción pedagógica supone. En este sentido, coincido con Luciano (2006: 168) cuando señala que la propuesta diferenciada e intercultural de la educación escolar indígena está siendo manipulada y cargada de estereotipos, y da señales de decadencia semántica y simbólica. Para él, es necesario pensar en nuevas propuestas que den cuenta de los deseos de los pueblos indígenas contemporáneos y que posibiliten una educación más articulada interculturalmente con los diferentes y complejos mundos en los que hoy transitan.

Como hemos visto hasta aquí, las políticas públicas dirigidas a fomentar la educación superior de los pueblos indígenas han estado enfocadas a la inclusión de esta población en las carreras comunes universitarias, a través de sistemas de cuotas, y a promover la formación específica para los maestros indígenas en las licenciaturas interculturales. Continúa el desafío de implementar políticas que garanticen la permanencia y la graduación exitosa de esos alumnos, la creación de carreras de buena calidad educativa que atiendan intereses diversificados de formación, y una transformación en las carreras convencionales para que se introduzcan nuevas perspectivas metodológicas, de enseñanza, investigación y extensión en consonancia con la diversidad y las formas de vida contemporáneas de la población indígena. 


\section{Bibliografía}

Almeida, Nina Paiva, 2008, Diversidade na Universidade: o BID e as políticas educacionais de inclusão étnico-racial no Brasil, tesis de maestría, Programa de Posgrado en Antropología Social, Universidad Federal de Río de Janeiro, Río de Janeiro.

Cajueiro, Rodrigo, 2008, "Os povos indígenas em instituições de ensino superior públicas federais e estaduais do Brasil: levantamento provisório de ações afirmativas e de licenciaturas interculturais", Projeto Trilhas de Conhecimentos. O Ensino Superior Indígena no Brasil, Laboratorio de Investigaciones en Etnicidad, Cultura y Desarrollo, Museo Nacional, Río de Janeiro.

Carvalho, José Jorge de y Rita Laura Segato, 2002, Uma proposta de cotas para estudantes negros e na Universidade de Brasília, Departamento de Antropología, Universidad de Brasilia, Brasilia (Serie Antropología, núm. 314). En línea: $<$ http://www.unb.br/ics/dan/Serie314empdf.pdf $>$.

Cordeiro, Maria José de Jesus Alves, 2007, “Tres anos de efetiva presença de negros e indígenas cotistas nas salas de aula da UEMS: primeiras análises”, en André A. Brandão (org.), Cotas raciais no Brasil. A primeira avaliação, DP\&A, Río de Janeiro, pp. 81-1114 (Col. Políticas da Cor).

Ferreira, Mariana L., 1992, Da origem dos homens à conquista da escrita: um estudo sobre povos indígenas e educação escolar no Brasil, tesis de maestría, Facultad de Filosofía, Letras y Ciencias Humanas, Universidad de São Paulo, São Paulo. IBGE, 2005, Tendências demográficas: uma análise dos indígenas com base nos resultados da amostra dos censos demográficos 1991 e 2000, Coordinación de Población e Indicadores Sociales, Instituto Brasileño de Geografía y Estadística, Río de Janeiro.

Luciano, Gersem J. dos Santos, 2006, O indio brasileiro: o que você precisa saber sobre os povos indígenas no Brasil de hoje, Ministerio de Educación y Cultura, Secretaría de Educación Continua, Alfabetización y Diversidad, Museo Nacional, Brasilia (Serie Vias dos Saberes, núm. 1).

_ 2009. "Indígenas no Ensino Superior: Novo Desafio para as Organizações Indígenas e Indigenistas no Brasil”, ponencia, 53 Congreso Internacional de Americanistas, Distrito Federal, México.

Maio, Marcos Chor y Ricardo Ventura Santos, 2006, "Políticas de cotas raciais, os 'olhos da sociedade' e os usos da antropologia: o caso do vestibular da Universidade de Brasília”, en Carlos Alberto Steil (coord.), Cotas raciais na Universidade, Universidad Federal de Rio Grande do Sul, Porto Alegre, pp. 35-52.

Nascimento, Adir C. y Antonio H. Aguilera Urquiza, 2008, "O Ensino Superior Indígena no Mato Grosso do Sul. Luta por autonomia e construção de políticas de sustentabilidade", ponencia, 26a Reunião Brasileira de Antropologia "Desigualdade na diversidade”, 1-4 de junio, Porto Seguro, Bahía.
Paladino, Mariana, 2001, Educação escolar indígena no Brasil contemporâneo: entre a revitalização cultural e a desintegração do modo de ser tradicional, tesis de maestría, Programa de Posgrado en Antropología Social, Universidad Federal de Río de Janeiro, Río de Janeiro.

Paulino, Marcos Moreira, 2008, Povos indígenas e ações afirmativas: O caso do Paraná, tesis de maestría, Facultad de Educación, Universidad Federal de Río de Janeiro, Río de Janeiro.

Repetto, Maxim, 2008, "Universidade e interculturalidade", en Universidade inconclusa: os desafíos da Desigualdade, Editora da Universidade Federal de Roraima, Boa Vista, pp. 33-54.

— Leandro Roberto Neves y Maria Luiza Fernandes, Universidade inconclusa: os desafíos da Desigualdade, Editora da Universidad Federal de Roraima, Boa Vista.

Santos, S. Augusto dos, 2005, "Introdução", en S. Augusto dos Santos (coord.), Ações afirmativas e combate ao racismo nas Américas, Ministerio de Educación y Cultura, Secretaría de Educación Continua, Alfabetización y Diversidad, Brasilia (Col. Educação para Todos), pp. 7-24.

Silva, Rosa Helena Dias da, 1998, A autonomia como valor e a articulação de possibilidades: um estudo do movimento dos professores indígenas de Amazonas, Roraima e Acre, tesis de doctorado, Facultad de Educación, Universidad de São Paulo, São Paulo.

Souza, Hellen de, 2003, Educação Superior para Indígenas no Brasil. Mapeamento provisório, Fundação Universidade do Estado de Mato Grosso, Instituto para la Educación Superior en América Latina y el Caribe, unEsco, Tangará da Serra.

Lima, Antonio Carlos, 1995, Um grande cerco de paz: poder tutelar, indianidade e formação de Estado no Brasil, Vozes, Petrópolis.

__, 2007, "Educación superior para indígenas en el Brasil: más allá de los cupos”, en Stella Maris García y Mariana Paladino (comps.), Educación escolar indígena. Investigaciones antropológicas en Brasil y Argentina, Antropofagia, Buenos Aires, pp. 257-277.

_ 2008 , "Sendas de conocimientos: la educación superior de indígenas en el Brasil. Una experiencia de fomento a acciones afirmativas en la educación superior", Isees, Fundación Equitas, Santiago de Chile, pp. 64-80.

_- y Maria Barroso-Hoffmann, 2004, Seminário "Desafiospara uma Educação Superior para os Povos Indígenas no Brasil". Políticas públicas de ação afirmativa e direitos culturais diferenciados, Museo Nacional, Universidad Federal de Río de Janeiro, Río de Janeiro. En línea: <http://www.trilhasdeconhecimentos.etc.br/livros/arquivos/Desafios.pdf $>$.

Steil, Carlos Alberto (comp.), 2006, Cotas raciais na Universidade, Universidad Federal de Rio Grande do Sul, Porto Alegre. 